\title{
Comment on "Bioaccumulation of Methyl Siloxanes in Common Carp (Cyprinus carpio) and in an Estuarine Food Web in Northeastern China"
}

\author{
Jaeshin Kim ${ }^{1}\left[\right.$ Kent Woodburn $^{1} \cdot$ Katie Coady $^{1} \cdot$ Shihe $\mathrm{Xu}^{1} \cdot$ Jeremy Durham $^{1} \cdot$ Rita Seston $^{2}$
}

Received: 23 June 2019 / Accepted: 16 October 2019 / Published online: 14 December 2019

(c) The Author(s) 2019

\begin{abstract}
We have reviewed a paper titled "Bioaccumulation of Methyl Siloxanes in Common Carp (Cyprinus carpio) and in an Estuarine Food Web in Northeastern China" by Xue et al., which was published in the Archives of Environmental Contamination and Toxicology in 2019. In the paper, the authors presented and discussed the measured bioconcentration factors (BCFs), biomagnification factors (BMFs), and trophic magnification factors (TMFs) of selected volatile methylsiloxanes in Shuangtaizi estuary in China. Although we appreciate their efforts for sample collection and data analysis, we have identified significant errors in calculations of BCFs, TMFs, and BMFs, as well as animal welfare issues and food web trophic level assumptions. Based on the data, we have attempted to correct some of the analysis and offered a more complete and robust interpretation of the related data, when possible. Collectively, these errors would likely lead to very different conclusions than yours in the paper.
\end{abstract}

\section{Summary of Xue et al. (2019)}

Xue et al. (2019) discussed bioaccumulation of volatile methylsiloxanes (VMS) in Shuangtaizi estuary located in the northeastern region of Bohai Sea, China (Xue et al. 2019). They determined three metrics to assess bioaccumulation: bioconcentration factor (BCF), biomagnification factor (BMF), and trophic magnification factor (TMF) for selected VMS. BCFs were measured based on an exposure test of common carp (Cyprinus carpio) for 32 days followed

Jaeshin Kim

jaeshin.kim@dow.com

Kent Woodburn

foxmoor1312@gmail.com

Katie Coady

kcoady@dow.com

Shihe $\mathrm{Xu}$

shihe.xu@dow.com

Jeremy Durham

jeremy.durham@dow.com

Rita Seston

hyla.environmental@gmail.com

1 Toxicology and Environmental Research and Consulting, The Dow Chemical Company, Midland, MI, USA

2 Hyla Environmental Consulting, LLC, Midland, MI, USA by 32 days of the depuration period. BMFs and TMFs were measured from biota samples that were collected in Shuangtaizi estuary. These collected samples included three different species of fish, eight different invertebrate species, and plankton.

Based on the measurement and data analysis, the authors concluded that:

- Octamethylcyclotetrasiloxane (D4) had strong bioconcentration potential (with a BCF of $6197 \mathrm{~L} \mathrm{~kg}^{-1}$ ),

- Decamethylcyclopentasiloxane (D5), dodecamethylcyclohexasiloxane (D6), and linear siloxanes (L7-10) were trophically magnified (with TMFs much $>1$ ) in a food chain, and

- D4-D6 and L7-L10 were biomagnified from planktons to Japanese snapping shrimp (with BMFs > 1).

In addition, the authors claimed that this is the first study to investigate the bioaccumulation behaviors of methyl siloxanes by coupling BCF and BMF with TMF.

\section{Critical Reviews}

Although the paper provided details of analytical methods and quality assurance and quality control (QA/QC) procedures, there are significant scientific errors in data analysis 
and biased selections of datasets to support their hypothesis of significant bioaccumulation of VMS.

\section{Measurement of BCFs}

The result of the exposure test with common carp is shown in Fig. 1 of Xue et al. (2019) with dry-weight (ng g-dw ${ }^{-1}$ ) biota concentrations of D4, D5, D6, D7, and L10 measured in muscle tissue over the duration of the study. The calculated uptake and clearance rates (i.e., $k_{1}$ and $k_{2}$, respectively) are shown in Table 1 of Xue et al. (2019). These rates and are based on regression curves using the equation $C_{F(t)}=\left(k_{1} / k_{2}\right) C_{w}$ $\left[1-\exp \left(-k_{2} t\right)\right]$ for the exposure period [Eq. 2 and Fig. 3 in Xue et al. (2019)] and the equation $C_{F}=C_{F 0} \exp \left(-k_{2} t\right)$ for the depuration period [Eq. 5 and Fig. 4 in Xue et al. (2019)]. We reproduced the regression results using the calculated values of $k_{1}$ and $k_{2}$ in the specified equations above and plotted measured biota concentrations and the regression curves (Fig. 1).

D4

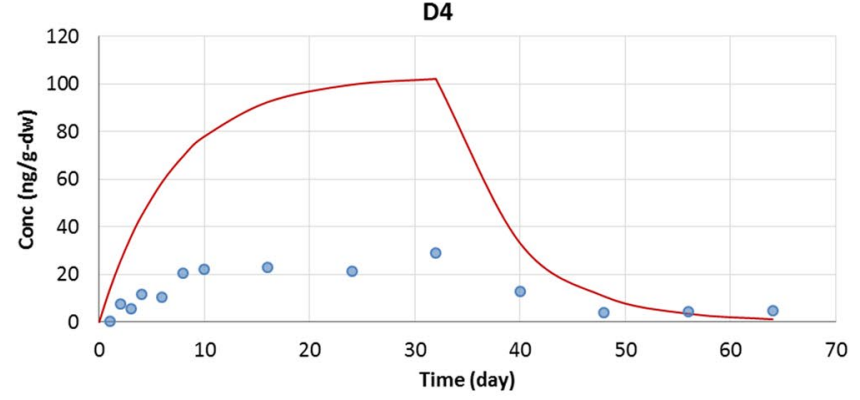

D6

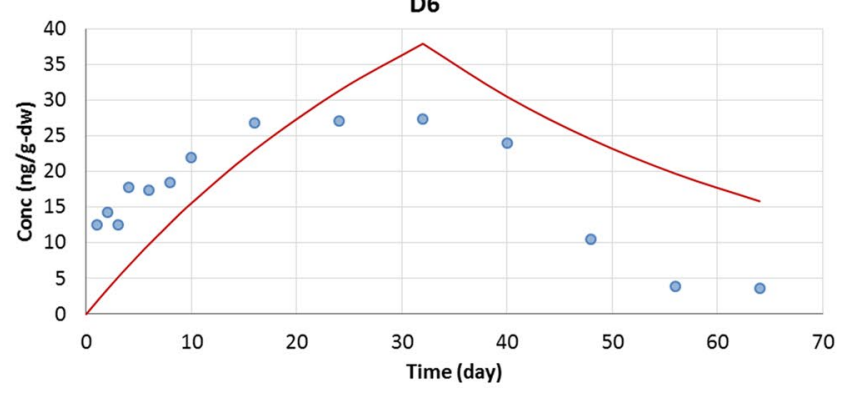

L10

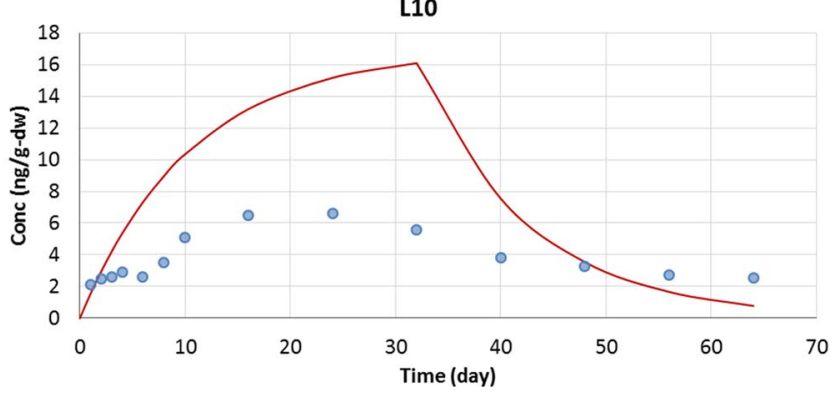

These plots clearly showed that the equations used to calculate update and depuration rates are not well-aligned with measured biota data. Furthermore, the lines in Fig. 3 of Xue et al. (2019) showing uptake do not start with the origin $\left(C_{F}=0\right.$ at $t=0$ in Eq. 2). This indicates that values of $k_{1}$ and $k_{2}$ in Table 1 are not strictly from the specified Eqs. 2 and 5 of Xue et al. (2019). In addition, there may be some contamination of the test fish according to the measurements where the test materials are detected in biota at an early phase of the exposure (i.e., Day 1). However, this issue was not discussed in the publication.

Plots in Fig. 4 of Xue et al. (2019) during the depuration phase were based on Eq. 5 that is a simple exponential decay function. However, the red lines in the plots are not such exponential function. The following plots are reconstructed using Eq. 5 optimized for the measured biota concentrations. These reproductions are not consistent with plots of Fig. 4. There is also an inconsistent data point. In Figs. 1d

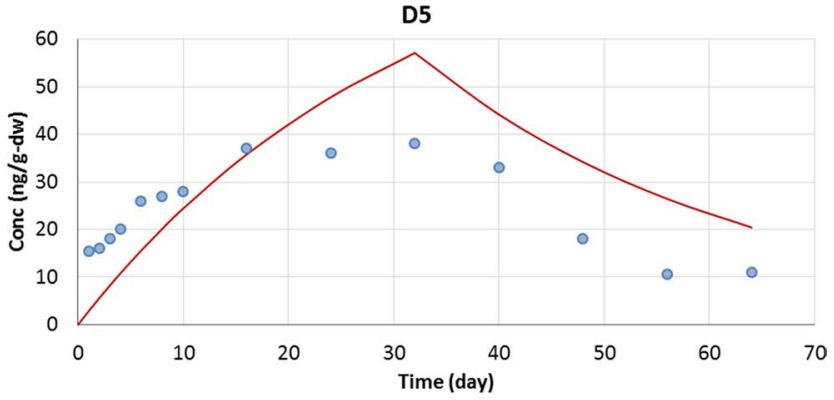

D7

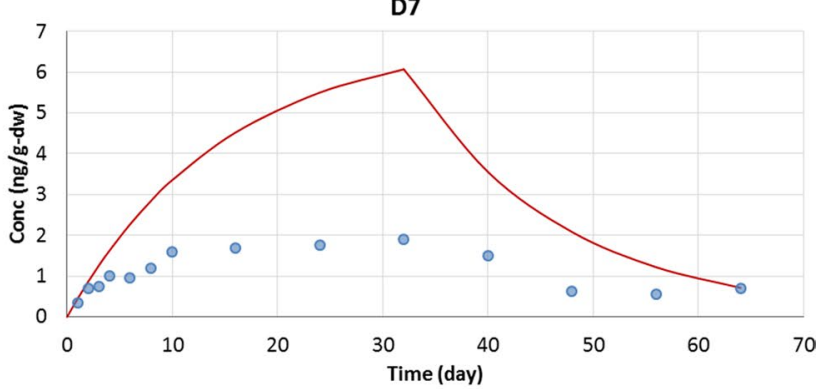

\begin{tabular}{lcc}
\hline Analyte & \multicolumn{2}{c}{ Bioconcentration kinetic parameters } \\
\cline { 2 - 3 } & $k_{1}\left(\text { day }^{-1}\right)^{\mathrm{a}}$ & $k_{2} \times 10^{-2}\left(\text { day }^{-1}\right)^{\mathrm{b}}$ \\
\hline $\mathrm{D}_{4}$ & 871.96 & 14.07 \\
$\mathrm{D}_{5}$ & 34.26 & 3.21 \\
$\mathrm{D}_{6}$ & 21.31 & 2.73 \\
$\mathrm{D}_{7}$ & 34.52 & 6.69 \\
$\mathrm{~L}_{10}$ & 39.97 & 9.46 \\
\hline
\end{tabular}

Fig. 1 Concentrations of D4, D5, D6, D7, and L10 (ng g-dw $\left.{ }^{-1}\right)$ during the periods of exposure (0-32 days) and depuration (32-64 days). The blue circles are measured biota concentration over time. The red lines are estimations of concentration during each period (i.e., Equa- tion 2 for exposure and Eq. 5 for depuration). Values of $k_{1}$ and $k_{2}$, shown in the bottom right, are from Table 1 of Xue et al. (2019). To convert dry-weight basis concentration to wet-weight basis concentration, the water content of the common carp was assumed to be $70 \%$ 
Table 1 Bioconcentration kinetic parameters of D4, D5, D6, D7, and L10 in common carp

\begin{tabular}{|c|c|c|c|c|c|c|}
\hline & \multicolumn{4}{|c|}{ Simultaneous fit: first-order Berkeley-Madonna modeling } & \multicolumn{2}{|c|}{$\begin{array}{l}\text { Sequential fit: first-order } \\
\text { elimination fit }\end{array}$} \\
\hline & $\begin{array}{l}k_{1}\left(\mathrm{~L} \mathrm{~kg}_{\mathrm{k}} \mathrm{ww}^{-1}\right. \\
\left.\mathrm{d}^{-1}\right)\end{array}$ & $k_{2}\left(\mathrm{~d}^{-1}\right)$ & 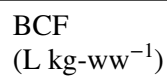 & Half-life (d) & $\overline{k_{2}\left(\mathrm{~d}^{-1}\right)}$ & Half-life (d) \\
\hline D4 & 184 & 0.11 & 1673 & 6 & 0.06 & 12 \\
\hline D5 & 47.5 & 0.076 & 625 & 9 & 0.05 & 14 \\
\hline D6 & 40.1 & 0.095 & 422 & 7 & 0.073 & 9 \\
\hline D7 & 13.9 & 0.075 & 185 & 9 & 0.037 & 19 \\
\hline L10 & 14.3 & 0.068 & 210 & 10 & 0.024 & 29 \\
\hline
\end{tabular}

Parameters $k_{1}$ (uptake rate constant) and $k_{2}$ (elimination rate constant) were optimized via first-order Berkeley Madonna modeling of uptake and elimination (simultaneous fit) and simple first-order sequential fit of the elimination data and $3 \mathrm{~d}$ of Xue et al. (2019), D7 concentration at Day 32 is $1.9 \mathrm{ng} \mathrm{g-dw}^{-1}$, but it is $1.7 \mathrm{ng} \mathrm{g-dw}^{-1}$ in Fig. $4 \mathrm{~d}$ (Fig. 2).

Because we found errors in the regression for the biota data in the publication, we also determined values of $k_{1}$ and $k_{2}$ by optimizing the parameters in Eqs. 2 and 5 via firstorder Berkeley Madonna modeling of uptake and elimination (simultaneous fit) and simple first-order sequential fit of the elimination data (Berkeley Madonna: Modeling and Analysis of Dynamic Systems Version 8.3.18, https:// berkeley-madonna.myshopify.com/). Note that the paper provided concentration information on a dry-weight basis and reported BCF values in wet-weight basis. Because no water content (or solid content) of the fish is known, 70\% of water content (or $30 \%$ of solid content) was assumed.
The results of optimized parameters from the new regression are shown in Table 1. The plots of measured biota concentration (in blue circles) and optimized uptake and depuration curves over time also are shown in Fig. 3. The plots show that the new regression curves are fitted to Eq. 2 and Eq. 5 much better than those of Xue et al. (2019) in Fig. 1. The new values of $k_{1}$ and $k_{2}$ are different from those of Xue et al. (2019), and the new BCF values are less than $2000 \mathrm{~L} \mathrm{~kg}^{-\mathrm{ww}^{-1}}$ for all VMS tested. Therefore, data analysis of the exposure test conducted by Xue et al. (2019) is likely incorrect and the BCF values cannot be accepted. Instead, a proper data analysis would support much lower BCF values for D4, D5, D6, D7, and L10 in common carp than those of Xue et al. (2019).

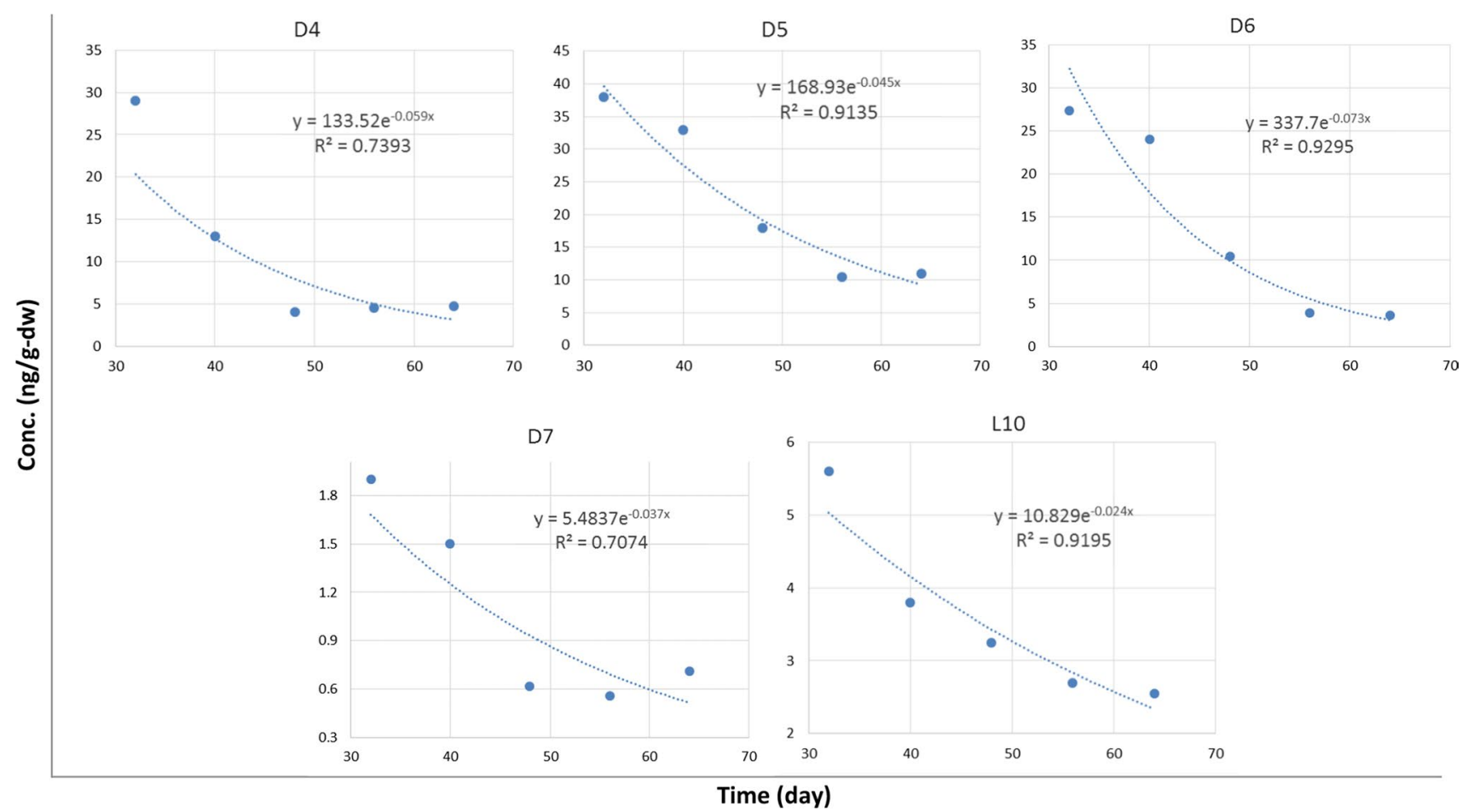

Fig. 2 Concentrations of D4, D5, D6, D7, and L10 (ng/g-dw) during the depuration period (32-64 days). The blue circles are measured biota concentration over time. The blue dotted lines are exponential regression curves based on Eq. 5 of Xue et al. (2019) 

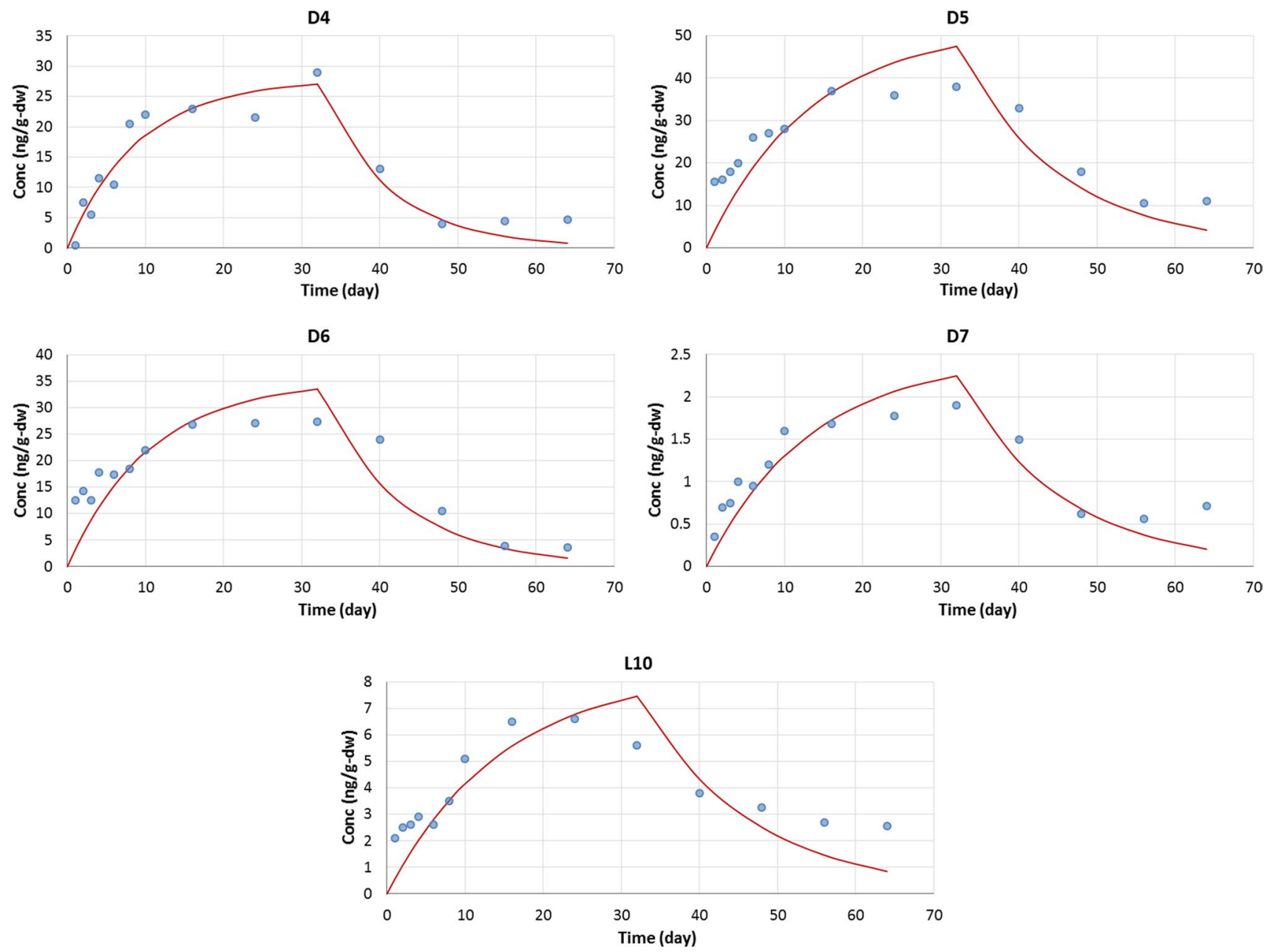

Fig. 3 Concentrations of D4, D5, D6, D7, and L10 (ng g-dw $\left.{ }^{-1}\right)$ during the periods of exposure (0-32 days) and depuration (32-64 days). The blue circles are measured biota concentration over time. The red lines are estimations of concentration during each period (i.e., Equation 2 for exposure and Eq. 5 for depuration). Values of $k_{1}$ and $k_{2}$

An additional factor in the carp BCF studies is the fact that the fish apparently were not fed during the 64-day experiments, which amounts to animal abuse in this case and resulted in the loss of body weight for the fish under study during the greater than 2-month testing period. Table S1 of Xue et al. (2019) shows significant decrease in body weight especially in the later phase of the test. However, OECD (2012) Guidelines 305 states in Item 45, "During the acclimation and test periods, to feed an appropriate diet of known lipid and total protein content to the fish in an amount sufficient to keep them in a healthy condition and to maintain body weight." All chronic assays, including fish BCF studies, conducted under U.S., Canadian, or European test guidelines require the feeding of fish for studies lasting longer than 4 days. It is entirely possible that this long time are from the new regression using the Berkeley Madonna program (Table 1). To convert dry-weight basis concentration to wet-weight basis concentration, the water content of common carp was assumed to be $70 \%$

period (64 days) without food could have altered uptake, elimination, and metabolic responses of the test species exposed to the cyclic and linear siloxane materials, thereby altering the $\mathrm{BCF}$ values produced during the experimental period.

Finally, the carp concentrations presented by Xue et al. (2019) are corrected for fish dry weight (dw) not fish wet weight (ww), which is the basis used for global regulatory expression of bioaccumulation (B) metrics. The laboratory method promulgated by the European Union for evaluation of fish BCF, OECD (2012) Guidelines 305 is based on use of wet weight or lipid weight concentration data and its interpretation for calculation of a guideline fish BCF value. Thus we suggest that the authors specify the units that used for the outcomes of the kinetic parameters and BCF values. 


\section{Measurement of TMFs}

Table 2 of Xue et al. (2019) compiles all the field biota concentrations of D4-D7 and L7-L10 on both a wet- and lipid-weight basis. Based on the data, TMFs were calculated based on the regression described in Eq. 8 and Eq. 9 of Xue et al. (2019). The plots of log-transformed biota concentrations versus trophic level (TL) are shown in Fig. 6, where only D5, D6, L7, L8, L9, and L10 are shown (not D4 or D7).

However, it should be noted that the plots only reflected one food chain in the food web (see Fig. 5 of Xue et al. 2019), more specifically: planktons ( $\mathrm{TL}=2.14) \rightarrow$ ark shell $(\mathrm{TL}=2.78) \rightarrow$ Neverita's albumen $(\mathrm{TL}=2.95) \rightarrow$ Chinese ditch prawn $(\mathrm{TL}=2.98)$. The paper failed to provide $\mathrm{TMF}$ values based on other food chains and all these measurements. Furthermore, the single food chain that was examined for deriving TMF values was based on small sample sizes of biota (e.g., $n=1$ for ark shell and $n=2$ for Chinese ditch prawn).

Because the real food-web in the test area is complex by nature, it is highly unlikely the simple food chain would represent environmental reality, and the small sample sizes of some of the biota in the examined food chain are too small to account for expected environmental variability (Borgå et al. 2012). Additionally, as the authors acknowledge, the enrichment relationship between the two isotopes $\left({ }^{13} \mathrm{C}\right.$ and $\left.{ }^{15} \mathrm{~N}\right)$ was not strong, and a proper food chain could not be established with any confidence. In particular, the ${ }^{15} \mathrm{~N}$ values that are typically used to calculate TL values (see Table S5 and Figure S2 of Xue et al. 2019) are all statistically equivalent values, with the exception of the "planktons" ${ }^{15} \mathrm{~N}$ value. Generally in aquatic food webs, the enrichment of ${ }^{15} \mathrm{~N}$ values from one trophic level to the next is approximately $2-5 \%$, with a generic value of ${ }^{15} \mathrm{~N}$ enrichment of $3.4 \%$ per trophic level step recommended for constructing food webs without a priori knowledge of the system (Deniro and Epstein 1981; Jardine et al. 2006; Minagawa and Wada 1984; Post 2002). Excluding the ${ }^{15} \mathrm{~N}$ value for "planktons," this level of ${ }^{15} \mathrm{~N}$ enrichment is entirely lacking in this aquatic system located in northeastern China.
These data do not support that the samples taken for this study are reflective of an existing food chain; therefore, calculation of TMF values from these samples is not supported as environmentally relevant.

In addition, regarding the specimen masses in the food chain, the prey-predator relationship in the food chain is unusual. The only ark shell collected was an individual with a mass of $71 \mathrm{~g}$ (not clear if this was with or without shell), the majority of the species which is indicated to prey upon the ark shell, Neverita albumen, a predatory snail, had masses ranging from 2.1 to $4.7 \mathrm{~g}$, with one individual of $17.9 \mathrm{~g}$. The "apex predator" of this food chain is the Chinese ditch prawn with specimen masses ranging from 1.0 to $3.7 \mathrm{~g}$. Although the ark shell $\rightarrow$ Neverita's albumen $\rightarrow$ Chinese ditch prawn may be a feasible food chain in this ecosystem, it seems highly unlikely that the individual specimens collected and analyzed here are reflective of that food chain. Individual size and life stage need to also be taken into consideration.

Thus it is strongly recommended to use all the data for TMF calculation because the real food-web is intrinsically incorporated in the assessment. Kidd et al. (2018) also suggested key principles for evaluation of TMF studies including a minimum food web TL difference of 2.0 and balance in the number of samples for low and high trophic level species. Using all the data in Table 2 of Xue et al. (2019), TMF were calculated as shown in Table 2 below [with TMFs of Xue et al. (2019) in the last column]. Plots of biota concentrations versus trophic level are shown in "Appendix 1" of this document.

As shown in Table 2, the plots of all the lipid-weight concentrations show trophic dilution $(\mathrm{TMF}<1)$ for D4, D5, D6, D7, and L7, whereas L8-L10 indicated TMF values above one. Especially when biota concentrations without plankton were used, the trends were improved (larger $R^{2}$ and smaller $p$ values) and all VMS have TMF $<1$ (from 0.05 to 0.96 ).

Because the authors presented TMFs based on the second food chain (FC-02) out of three, it would be appropriate to test the other food chains (FC-01 and FC-03) to examine the complete data set, rather than only assessing one
Table 2 Recalculation of trophic magnification factors (TMFs) using all the biota data of Shuangtaizi estuary, China, in Table 2 of Xue et al. (2019)

\begin{tabular}{|c|c|c|c|c|c|c|c|}
\hline \multirow[t]{2}{*}{ VMS } & \multicolumn{3}{|c|}{ Without plankton } & \multicolumn{4}{|c|}{ With plankton } \\
\hline & TMF & $R^{2}$ & $p$ val & $\mathrm{TMF}$ & $R^{2}$ & $p$ val & TMF (Xue et al. 2019) \\
\hline D4 & 0.081 & 0.4701 & $1.99 \mathrm{E}-02$ & 0.459 & 0.1134 & $2.85 \mathrm{E}-01$ & Not provided \\
\hline D5 & 0.137 & 0.3031 & $7.93 \mathrm{E}-02$ & 0.411 & 0.1530 & $2.09 \mathrm{E}-01$ & 11.0 \\
\hline D6 & 0.051 & 0.3292 & $6.50 \mathrm{E}-02$ & 0.480 & 0.0492 & $4.88 \mathrm{E}-01$ & 7.1 \\
\hline D7 & 0.041 & 0.3491 & $5.56 \mathrm{E}-02$ & 0.378 & 0.0816 & $3.68 \mathrm{E}-01$ & Not provided \\
\hline L7 & 0.033 & 0.3544 & $5.33 \mathrm{E}-02$ & 0.664 & 0.0116 & $7.39 \mathrm{E}-01$ & 10.0 \\
\hline L8 & 0.198 & 0.2859 & $9.01 \mathrm{E}-02$ & 1.026 & 0.0002 & $9.70 \mathrm{E}-01$ & 6.6 \\
\hline L9 & 0.461 & 0.0364 & $5.74 \mathrm{E}-01$ & 1.828 & 0.0463 & $5.02 \mathrm{E}-01$ & 5.3 \\
\hline L10 & 0.959 & 0.0001 & $9.77 \mathrm{E}-01$ & 1.783 & 0.0445 & $5.10 \mathrm{E}-01$ & 3.0 \\
\hline
\end{tabular}


potential food chain. TMFs for each food chain were calculated and shown below. The results clearly show that the authors "cherry-picked" the second food chain to demonstrate trophic magnifications of VMS. Although the authors' TMF values should be relevant to TMFs of FC-02, we cannot reproduce their calculations exactly. One reason might be that we used average values for each species provided in Table 2 of Xue et al. (2019), whereas authors might use individual data points. Additional plots of lipid-weight concentrations versus trophic level are shown in "Appendix 2" of this document (Table 3).

The results clearly showed that TMFs of D4, D5, D6, D7, and $\mathrm{L} 7$ are less than 1 for FC-01 and FC-03, although they are greater than 1 for FC-02. Given that the biota plots of all data points (rather than individual food chain) are known, conclusions based on only FC-02 cannot be accepted without providing obvious reasons to exclude TMF values for FC-01 and FC-03. Again, because there are significant uncertainties around isotopic ratios, representative species (limited sample sizes and narrow range of trophic level), and the food chains proposed by Xue et al. (2019), it is recommended to calculate TMFs incorporating uncertainties of food chains and to include all the measurement of biota concentrations which are the outcomes of complex food-webs.

\section{Measurement of BMFs}

Authors calculated BMFs of VMS from planktons (TL 2.14) to Japanese snapping shrimp (TL 2.59) using Eq. 10 in Xue et al. (2019). The calculated BMFs were greater than 1 for D4-D6 and L7-L10, indicating biomagnification from the prey-predator relationship. These BMF values were not able to be completely reproduced; relatively large differences between the two calculations were observed especially for D5, D6, L7, and L8 (see the table below).

Table 3 Trophic magnification factors (TMFs) calculated for each food chain established by Xue et al. (2019)

\begin{tabular}{llrll}
\hline & \multicolumn{3}{l}{ TMF (with plankton) } \\
\cline { 2 - 5 } & FC-01 & FC-02 & FC-03 & FC-02 (Xue et al. 2019) \\
\hline D4 & 0.41 & 2.77 & 0.62 & Not provided \\
D5 & 0.47 & 1.53 & 0.46 & 11.0 \\
D6 & 0.48 & 5.25 & 0.62 & 7.1 \\
D7 & 0.37 & 4.06 & 0.51 & Not provided \\
L7 & 0.92 & 13.03 & 0.90 & 10.0 \\
L8 & 1.26 & 4.13 & 1.28 & 6.6 \\
L9 & 3.53 & 5.82 & 1.75 & 5.3 \\
L10 & 1.71 & 3.49 & 1.99 & 3.0 \\
\hline
\end{tabular}

\begin{tabular}{lccccccccc}
\hline Species & TL & D4 & D5 & D6 & D7 & L7 & L8 & L9 & L10 \\
\hline $\begin{array}{l}\text { Concentration } \\
\left(\mathrm{ng} \mathrm{g}^{-1 w^{-1}} \text { ) }\right.\end{array}$ & & & & & & & \\
$\begin{array}{l}\text { Japanese } \\
\text { snapping } \\
\text { shrimp }\end{array}$ & 2.59 & 750 & 181 & 612 & 364 & 520 & 113 & 108 & 99.4 \\
$\begin{array}{l}\text { Planktons } \\
\text { BMF }\end{array}$ & 2.14 & 239 & 156 & 141 & 103 & 60.1 & 30.2 & 30.2 & 39.3 \\
$\begin{array}{l}\text { Xue et al. } \\
\text { (2019) }\end{array}$ & 3.2 & 5.2 & 9.0 & $-^{\mathrm{a}}$ & 11 & 9.2 & 3.4 & 2.2 \\
$\begin{array}{c}\text { New cal- } \\
\text { culation }\end{array}$ & 2.59 & 0.96 & 3.59 & 2.92 & 7.15 & 3.09 & 2.95 & 2.09 \\
\hline
\end{tabular}

${ }^{\text {a}}$ Not provided

The authors evaluated BMFs from just one prey-predator relationship, but not many other relationships in the food-web in Shuangtaizi estuary. Since TMF is basically an average of BMFs of all prey-predator relationships, it is expected that most BMFs are less than one for all VMS at higher trophic levels (see "Appendix 1" for biota concentrations versus trophic level without plankton). Because the authors' knowledge of the food web is not demonstrated in the text nor does the uniformity of the ${ }^{15} \mathrm{~N}$ data give information concerning prey/predator relationships in the food web, the presentation of BMF values in this paper is nearly a random ratio of concentrations of VMS in various species. The authors came to a premature conclusion considering only one set of biomagnification data. It is recommended to evaluate BMFs for other prey-predation relationships with exclusion of plankton (as discussed above). This would eventually lead to a more relevant discussion on TMFs of VMS.

\section{Claiming the First Study of Coupling BCF and BMF with TMF}

The authors claimed, "This is the first study to investigate the bioaccumulation behaviors of methyl siloxanes by coupling BCF and BMF with TMF." In our opinion, however, "coupling" has not been conducted in the newest sense. All the TMF studies include BMF by default. Here the BCF measurement was one thing (with Common carp) and the TMF measurement was another. No same biota species were tested for both BCF and TMF to couple the two metrics. Since authors did not trace the origin of the common carp that were bought from a local market, there was no valid evidence that the fish were from the same field sampling area examined for TMF derivation.

\section{Analytical Concerns}

The authors stated they tried to reduce the contamination of VMS in sampling, treatment and analysis stages. However, it is very unlikely they would be able to achieve the LOD 
in water of $0.1-1 \mathrm{ng} \mathrm{L}^{-1}$ using a DB-5 column. GC-MS analysis in samples are often plagued by elevated levels due to low bleed rubber septa and PDMS based columns such as the DB-5 used (Varaprath et al. 2000, 2006), alternatives columns and GC-MS components are available were not utilized by the researchers.

The LOD and LOQ determinations are not well defined in the paper. There is no information provided regarding the number of replicates or the concentration of internal standard that was spiked to all samples. The authors state that procedural blanks were done with every 10 samples, however Table S4 shows blanks 1-14 only for biota samples (indicated by the unit, ng/g-ww in the caption) but not for water samples. Additionally, the blanks were presented as a concentration, but typically procedure blanks are presented as an amount.

\section{Lack of VMS Concentrations in Sediment and Water}

VMS concentration in sediment in Bohai Sea has a strong gradient along the coastlines, which indicates that the exposure levels to biota species are different from location to location (Zhi et al. 2019). It is strongly recommended to measure VMS concentrations in sediment and water to evaluate the degree of exposure of benthic invertebrates and fish for different sampling locations. Zhi et al. (2019) concluded that all cyclic and linear VMS (D4-D6 and L5-L16) in benthic mollusks sampled from seven different locations in Bohai Sea, China showed biota-sediment accumulation factors (BSAF) much less than 1.7, indicating less potential bioaccumulation for VMS.

\section{Minor Typos}

- Joyner's tonguesole (Arelicus joyneri gunther) in Section "Food Web Sample Collection": gunther is not a genus nor species. Günther is a researcher who studied this species. Correction: joyner's tonguesole (Arelicus joyneri).

- The unit of $k_{1}$ in Table 1 is $\mathrm{day}^{-1}$. It should be $\mathrm{L} \mathrm{kg-ww}{ }^{-1}$ day $^{-1}$.

- In Table S2, the unit of body length of biota samples is $\mathrm{cm}$. It should be $\mathrm{mm}$.

\section{Conclusions}

We have reviewed the data, methods, and overall analysis of the paper published by Xue et al. (2019). There are clear errors in study conduct and standardization of data and measurements, animal welfare issues, food web trophic level assumptions, sample collection issues, and incorrect calculations of BCFs, TMFs, and BMFs. Collectively, these errors in collection, analysis, and judgment would likely lead to very different conclusions than those offered by the authors in the publication. In this analysis, we have attempted to correct some of the analysis and offer a more complete and robust interpretation of some of the data, when possible.

The siloxane BCF values were recalculated using OECD standard methods and all tested siloxane values were $<2000 \mathrm{~L} \mathrm{~kg}-\mathrm{ww}^{-1}$, indicating that none of the materials would be considered "B" per common regulatory guidance. The reanalyzed TMF values (without plankton) were all less than 1, confirming using field data that VMS did not exhibit biomagnification via the food web for Shuangtaizi estuary in China.

Based on our careful review, the paper contains significant errors in data analysis and inconsistent data interpretation as well as erroneous conclusions. Thus, we suggest the editors of Archives of Environmental Contamination and Toxicology request the authors to withdraw the publication from Archives of Environmental Contamination and Toxicology, although we respect the editor's initial decision.

Open Access This article is distributed under the terms of the Creative Commons Attribution 4.0 International License (http://creat ivecommons.org/licenses/by/4.0/), which permits unrestricted use, distribution, and reproduction in any medium, provided you give appropriate credit to the original author(s) and the source, provide a link to the Creative Commons license, and indicate if changes were made.

\section{Appendix 1: Biota Concentrations of Each VMS (ng/g-lw) Versus Trophic Level, All Data}


Without Plankton

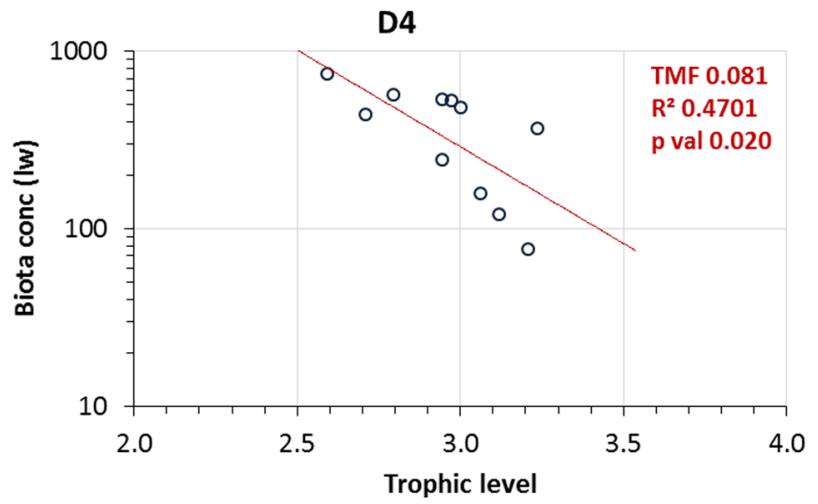

D5

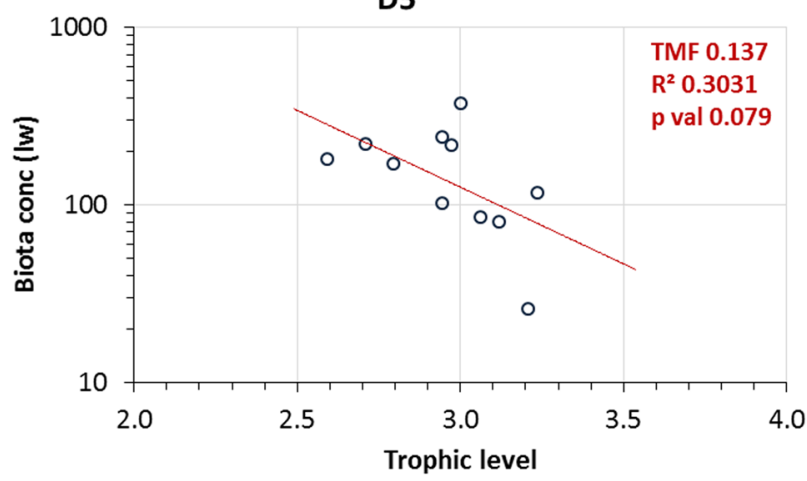

D6

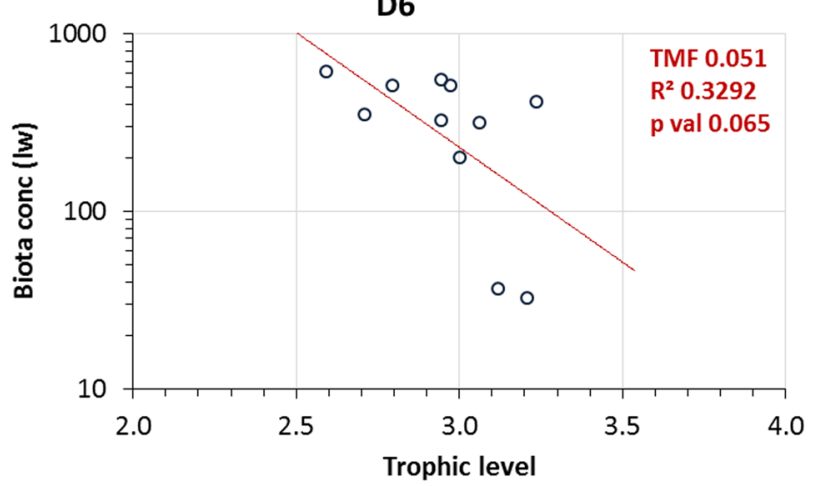

D7

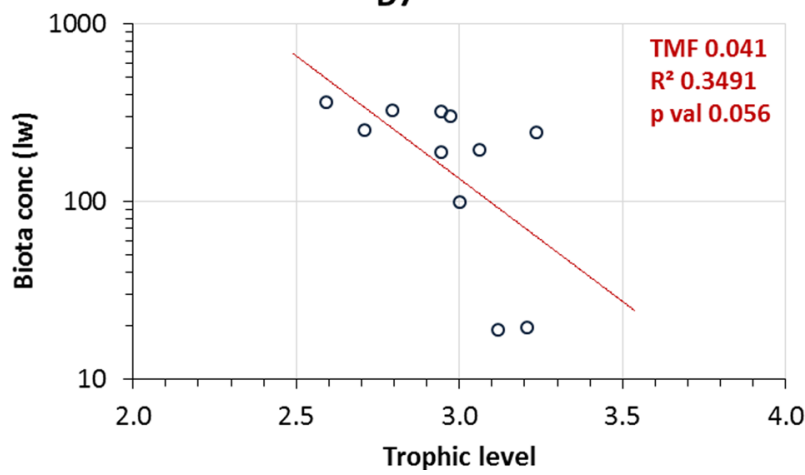

With Plankton

D4

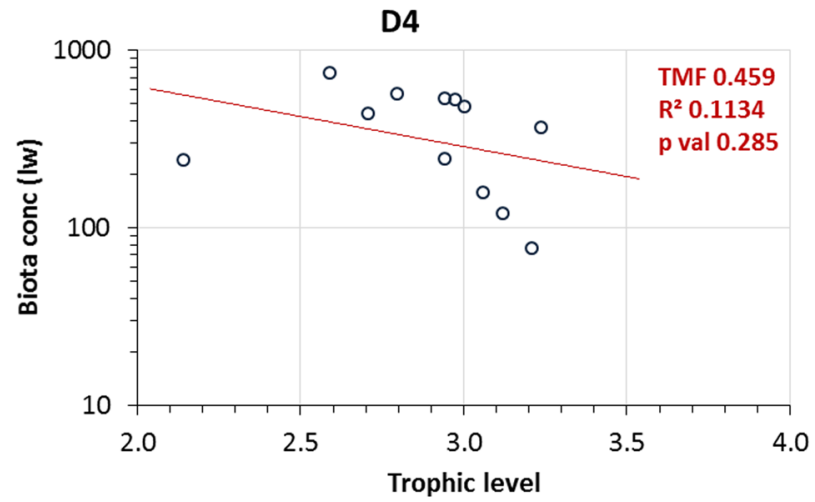

D5

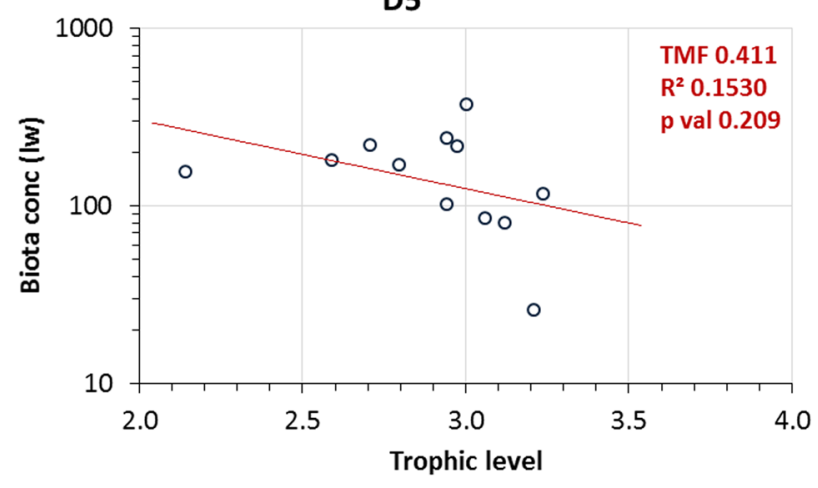

D6

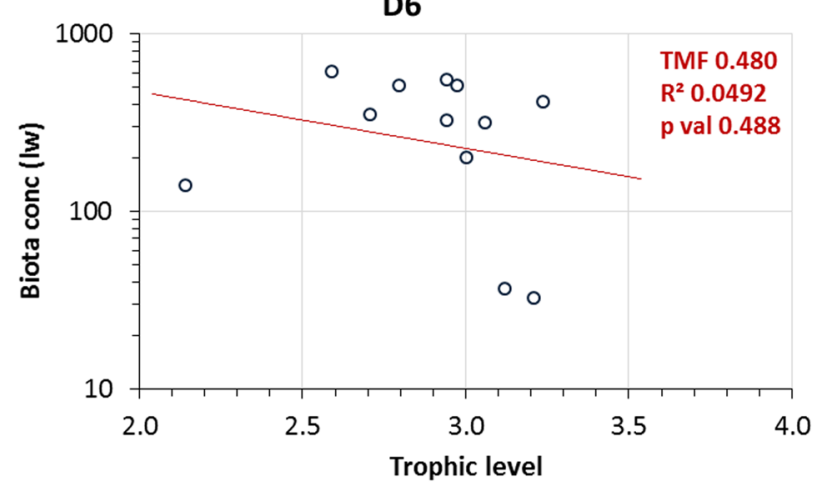

D7

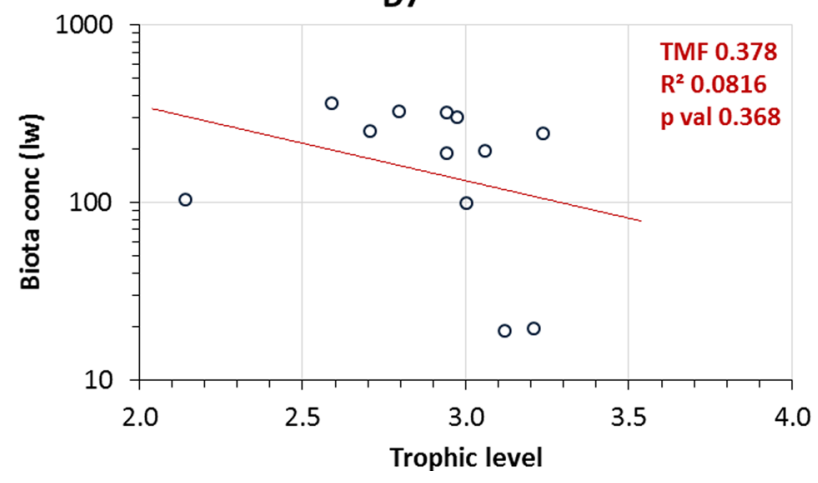




\section{Without Plankton}

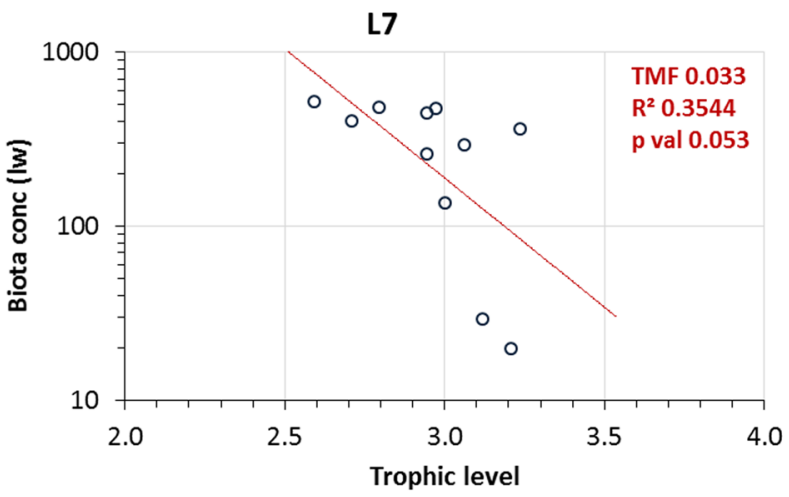

L8

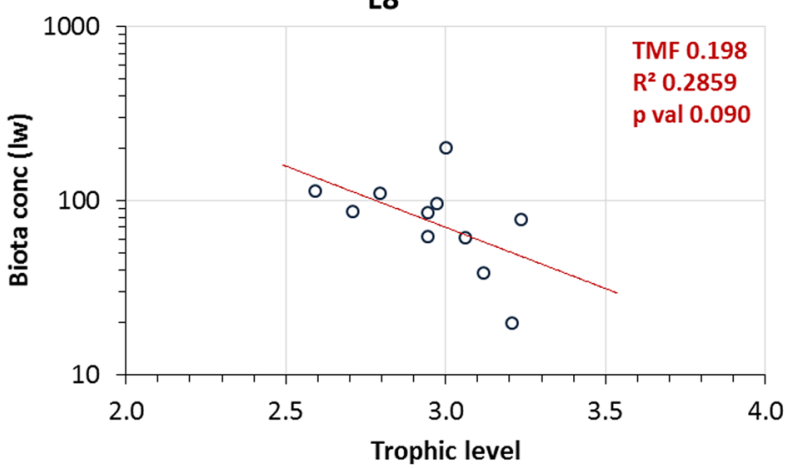

L9

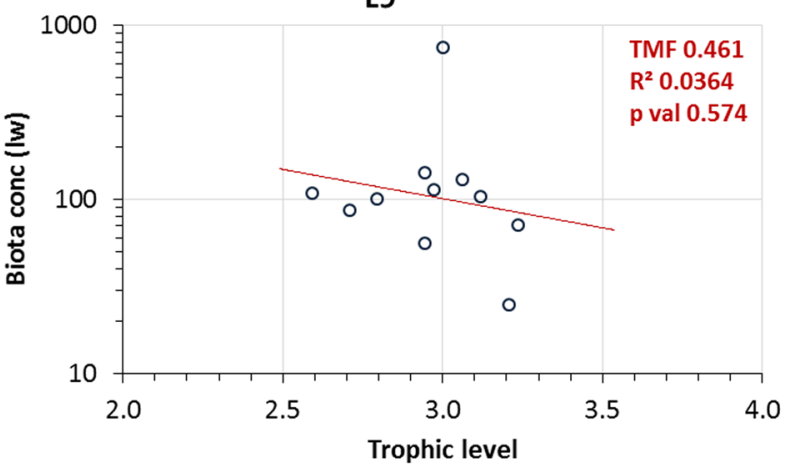

L10

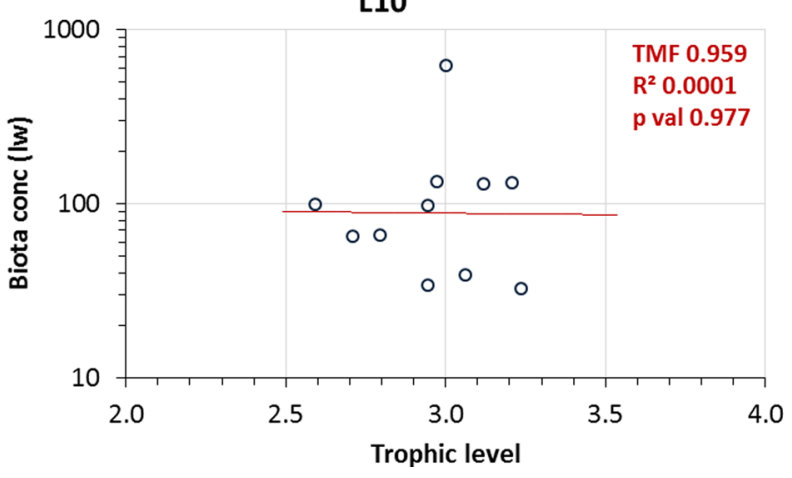

With Plankton

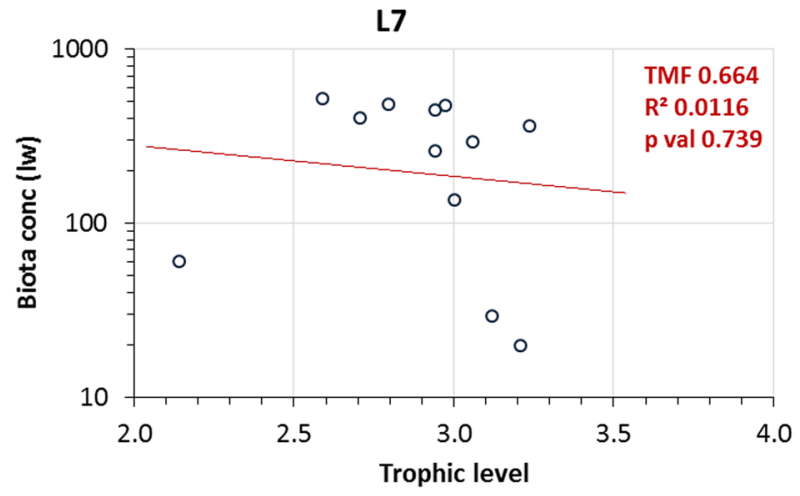

L8

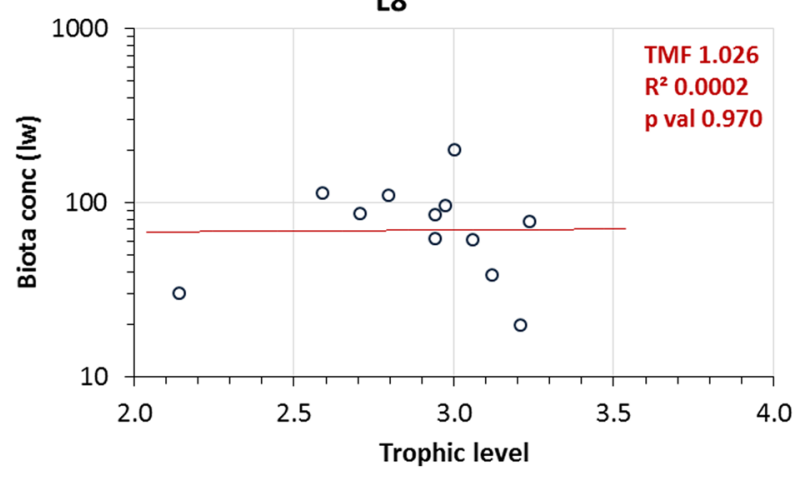

L9

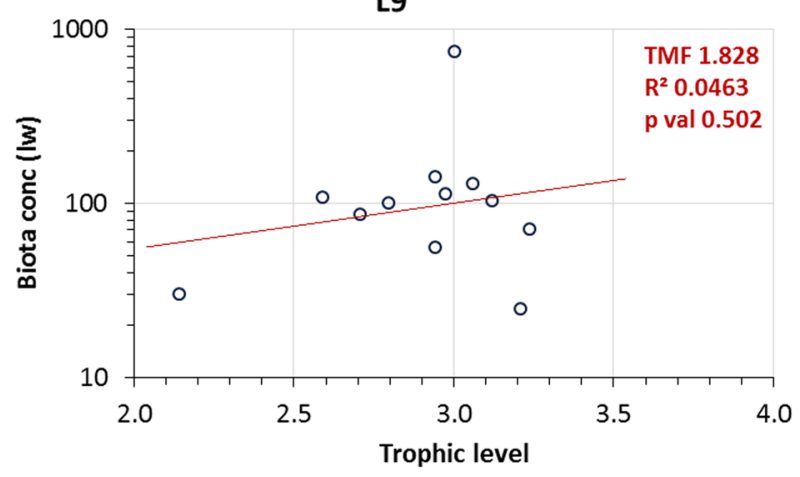

L10

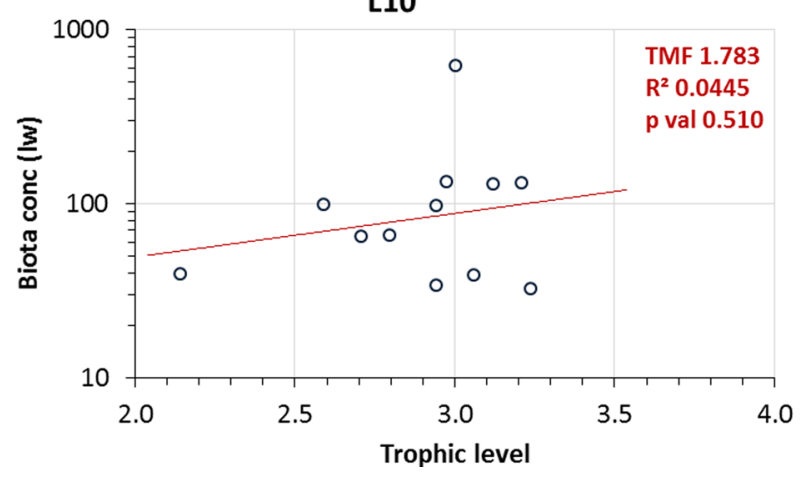


Appendix 2: Biota Concentrations of Each VMS (ng/g-lw) Versus Trophic Level for Each Food Chain

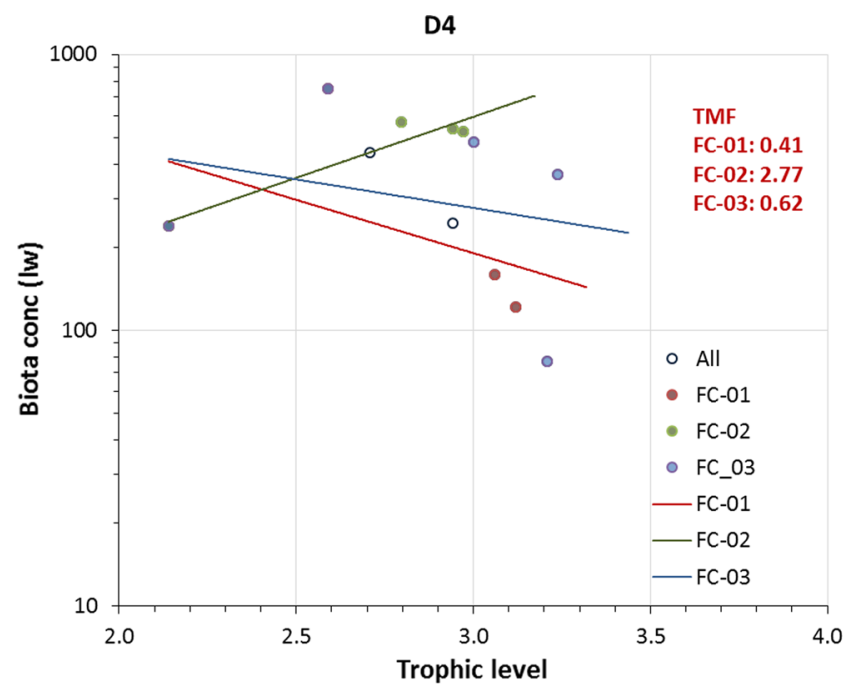

D6

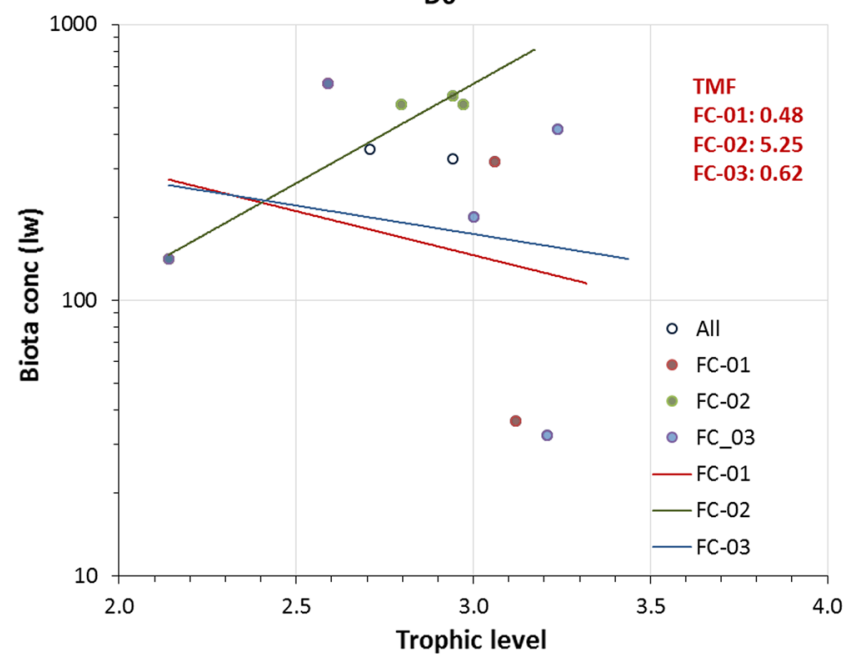

L7

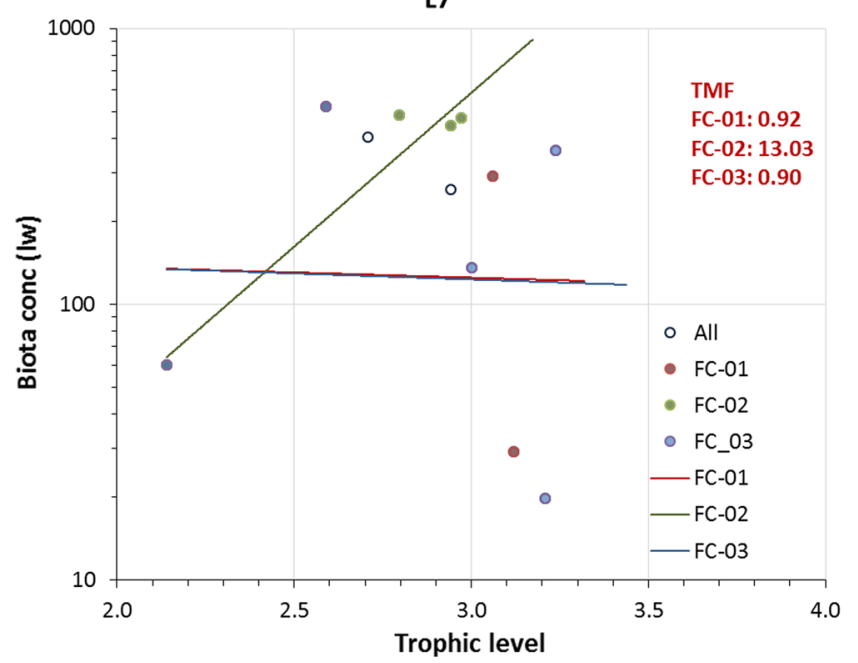

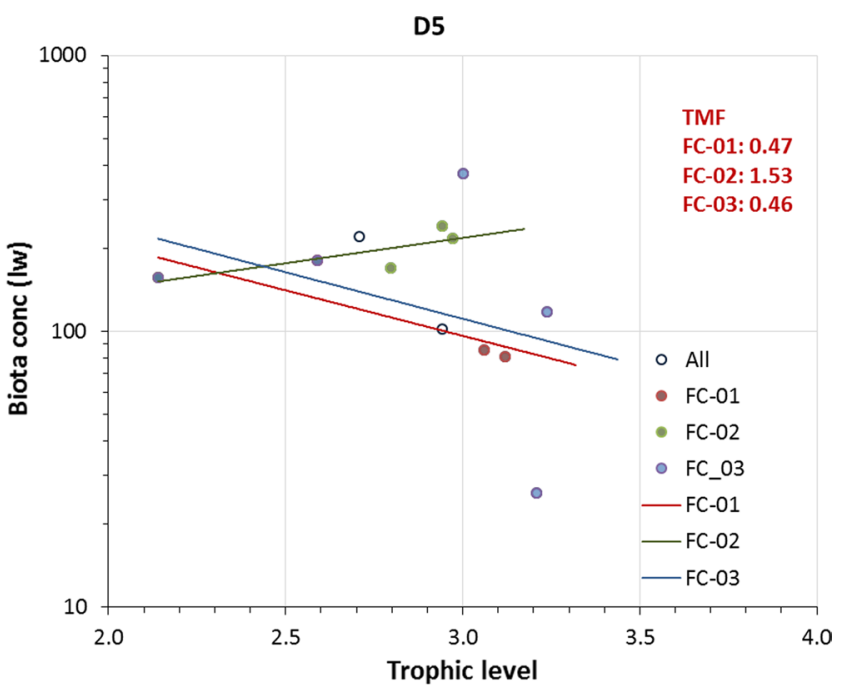

D7

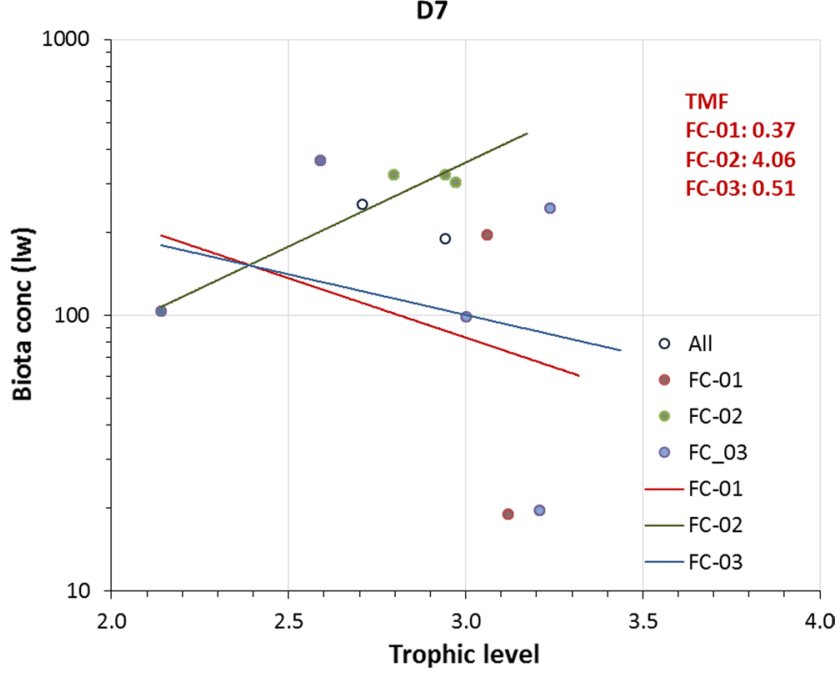

L8

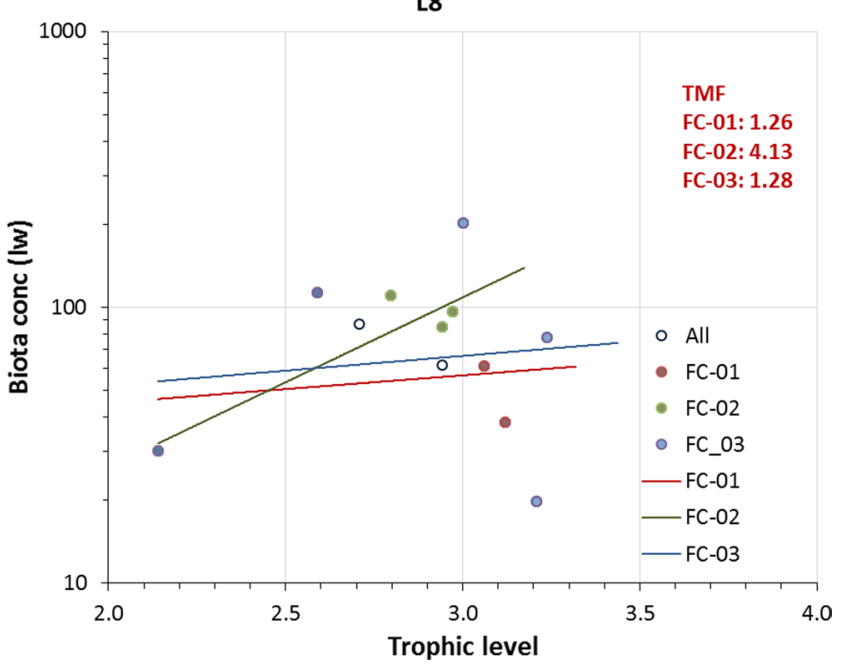


L9

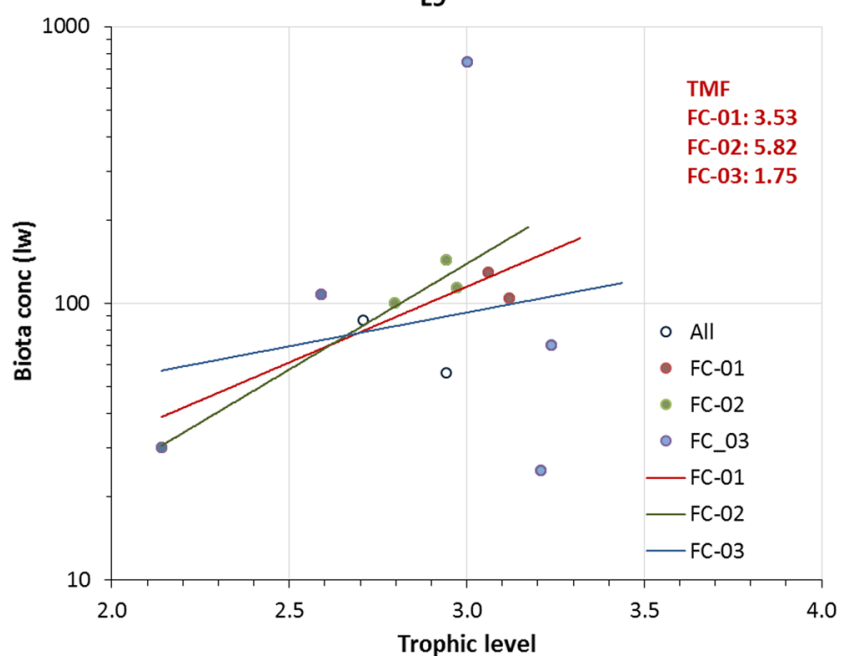

\section{References}

Borgå K, Kidd KA, Muir DCG, Berglund O, Conder JM, Gobas FAPC et al (2012) Trophic magnification factors: considerations of ecology, ecosystems, and study design. Integr Environ Assess Manag 8:64-84

Deniro MJ, Epstein S (1981) Influence of diet on the distribution of nitrogen isotopes in animals. Geochim Cosmochim Acta 45:341-351

Jardine TD, Kidd KA, Fisk AT (2006) Applications, considerations, and sources of uncertainty when using stable isotope analysis in ecotoxicology. Environ Sci Technol 40:7501-7511

Kidd KA, Burkhard LP, Babut M, Borgå K, Muir DC, Perceval O et al (2018) Practical advice for selecting or determining trophic magnification factors for application under the European Union water framework directive. Integr Environ Assess Manag 15:266-277

Minagawa M, Wada E (1984) Stepwise enrichment of $15 \mathrm{~N}$ along food chains: further evidence and the relation between $815 \mathrm{~N}$ and animal age. Geochim Cosmochim Acta 48:1135-1140

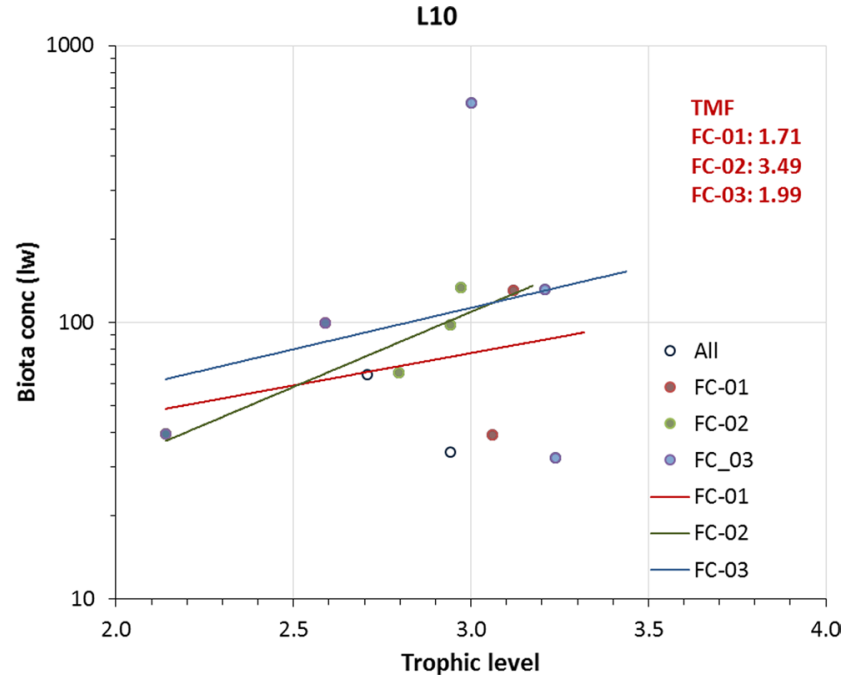

OECD (2012) Test No. 305: Bioaccumulation in Fish: Aqueous and Dietary Exposure: OECD Guidelines for the Testing of Chemicals, Section 3, OECD Publishing, Paris. https://doi.org/10.1787/97892 64185296-en

Post DM (2002) Using stable isotopes to estimate trophic position: models, methods, and assumptions. Ecology 83:703-718

Varaprath S, Seaton M, McNett D, Cao L, Plotzke KP (2000) Quantitative determination of octamethylcyclotetrasiloxane (D4) in extracts of biological matrices by gas chromatography-mass spectrometry. Int J Environ Anal Chem 77:203-219

Varaprath S, Stutts DH, Kozerski GE (2006) A primer on the analytical aspects of silicones at trace levels-challenges and artifacts: a review. Silicon Chem 3:79-102

Xue X, Jia H, Xue J (2019) Bioaccumulation of methyl siloxanes in common carp (Cyprinus carpio) and in an estuarine food web in Northeastern China. Arch Environ Contam Toxicol 76(3):496-507

Zhi L, Xu L, He X, Zhang C, Cai Y (2019) Distribution of methylsiloxanes in benthic mollusks from the Chinese Bohai Sea. J Environ Sci 76:199-207 